\title{
An Experimental Study of Integrating LEGO Robots Instruction into the "Engine Principles and Practice" Curriculum at Automobile Departments in Vocational Schools
}

\author{
Tsai-Ku Liao, Chin-Wen Liao, Chia-Ling Shih, and Chang-Fu Lin
}

\begin{abstract}
The previous researchers indicate that the only core subject related to automobile is the integrated "engine principles and practice" curriculum in the second semester of the first year of vocational high school in Taiwan, students are really difficult to understand the core knowledge of automobile. This study intended to investigate the influence of integrating LEGO robots into instruction of the curriculum at the automobile departments. In order to achieve the purpose, the method of quasi-experimental pretest-posttest design was used in this study. The object of the study contained 96 students of two classes at the 10th grade. The experimental group was integrated LEGO Robots course, while the control group was given a traditional instruction. The experiment lasted for twelve weeks. The main research results are: when integrating LEGO robots into instruction, students' learning effectiveness both on subjects and practical subjects are better than traditional teaching. The experiment group students have significant positive correlation between learning effectiveness and learning attitude.
\end{abstract}

Index Terms-Experimental investigation, engine principles and practice, LEGO robots, learning effectiveness.

\section{INTRODUCTION}

\section{A. Research Background and Motivation}

Technical and vocational education is always an important and unique part of Taiwan's education system, which intends to incubate practical talents along with the cooperation of national economic and industrial development [1]. By reviewing previous economic development in Taiwan, it is not difficult to find that even Taiwan lacks of resources for developing industries, it still can incubate diversified technical manpower from the technical and vocational education [2]; as a result, it created Taiwan's economic miracle at present. As being the basic-level teachers of the technical and vocational education system, who should make their best effort to look for innovation and change in teaching, and anticipate incubating useful talents for our country and society.

Among these subjects as required by the Ministry of

The authors are with the Department of Industrial Education and Technology, National Changhua University of Education, Changhua, Taiwan (e-mail: tsaikuliao@gmail.com, malisa168@yahoo.com.tw, terence650607@hotmail.com, tcwliao@cc.ncue.edu.tw).
Education, the only core subject related to automobile is the integrated "engine principles and practice" curriculum in the second semester of the first year of vocational high school, in such a situation, students are really difficult to understand the core knowledge of automobile [3], [4]. Moreover, with the changes in testing subjects, such as in Profession Class 1 the testing subjects have changed to Applied Mechanics and Engine Principles and Practice, and Introduction to Electrical Engineering and Practice and Introduction to Electronics and Practice in Profession Class 2 [5]. For so long, "teaching to the test" has existed in domestic education system, thus in order to cope with the competition for schooling, most curriculums are centralized at related subjects in Four/Two-year College Program Entrance Exam when each school designed its own courses, which made the school-based curriculum to be nothing but nominal only [6], [7]. Therefore, how to activate students'. learning motivation and make this course of Engine Principles and Practice to get better learning effectiveness; in addition, it is also one of research motivations in this study.

Whether vocational high schools integrated LEGO robot sets (9797-LEGO® MINDSTORMS ${ }^{\circledR}$ Education Base Set) into the practical courses at automobile department that will cause a significant transfer for learning or not? Then, it could make improvement in students' original practical training, thus it is the second research motivation of this study.

\section{B. Research Purpose}

According to aforesaid research motivations, purposes of this research are as follows:

1) Investigates the integration of LEGO robots into the engine principles and practice affecting learning effectiveness on students at the automobile department in vocational school students.

2) Investigates the integration of LEGO robots into the engine principles and practice affecting learning attitude on students at the automobile department in vocational school students.

3) Proposes suggestions in accordance with research results to become the reference to related teaching of practice courses at the automobile department.

\section{RESEARCH DESIGN AND IMPLEMENTATION}

\section{A. Research Framework}

Research purpose and related literature review of this study are composed of this diagram of research framework, as shown in Fig. 1: 


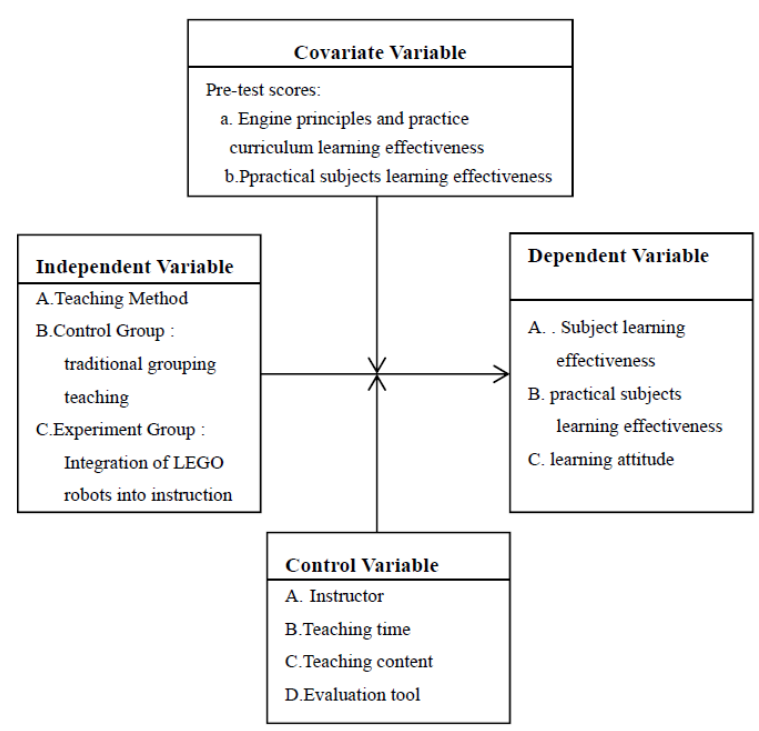

Fig. 1. Research framework diagram.

\section{B. Research Object}

The research sample of this study is adopted the first year first-year students from 2 classes at the automobile maintenance department of a private senior high school in Changhua County. The experiment is used the pre-test results of the engine principles and practice to make S-shaped grouping for the experiment group and control group to avoid the homogeneous grouping from happening.

\section{Research Method}

Within the experimental teaching, this study applied the following tools: "exam paper of learning effectiveness on the subject of engine principles and practice curriculum", "exam paper of learning effectiveness on the practical subject of engine principles and practice curriculum" and "learning attitude questionnaire", as the research method.

\section{Research Implementation}

\section{1) Pre-test implementation phase}

After confirmed the research method, in March 2014, the official pretest exam paper of learning effectiveness on the subject of engine principles and practice curriculum has been implemented to understand students of these 2 classes for their academic ability and level before implementing the experimental teaching; moreover, as for the practical subjects, the semester grades of these following professional subjects: Workshop Practice, Mechatronics Drawing and Practice I and Motorcycle Practice, for the first semester of the first year that would be adopted as the pre-test grades of practical subjects, so as to eliminate the influence that caused by different basic abilities of the practical subjects.

\section{2) Experimental teaching phase}

In the experimental teaching, the control group used general and traditional teaching methods with instruction, demonstration and exercise only. However, the experiment group has integrated the LEGO robots teaching into the original curriculum for future teaching materials.

\section{3) Post-test implementation phase}

The experimental teaching curriculum has completed in May of the same year, and took measurements respectively from the "official pretest exam paper of learning effectiveness on the subject of engine principles and practice curriculum" and "engine principles and practice curriculum learning attitude questionnaire"; however, for practical subjects, the teaching schedule is applied to test the practical subjects : Test 1 "disassembly, assembly and measurement of four-stroke single cylinder piston" and Test 2 "investigation of fuel injection engine components and use of diagnostic apparatus" within two weeks.

\section{RESEARCH CONTROL AND LIMITATION}

The scope and limitations of this study are described below:

\section{A. Research Control}

1) This study is divided into the experiment group and control group and implement the quasi-experimental design in the "engine principles and practice" curriculum, where to implement the integration of LEGO robots into instruction in the experiment group, and the traditional teaching method in the control group.

2) The teaching contents of this study is mainly used the subject of engine principles and practice at the automobile department in vocational school, and carried out a 12-week with total 48 hours experimental teaching, as shown in Table I.

TABLE I: RESEARCH DESIGN AND CONTROL FACTORS

\begin{tabular}{llll}
\hline Group & Pre-test & $\begin{array}{l}\text { Experimental } \\
\text { Treatment }\end{array}$ & Post-test \\
\hline $\begin{array}{l}\text { Experiment } \\
\text { Group }\end{array}$ & $\mathrm{O} 1$ & $\mathrm{X} 1$ & $\mathrm{O} 2$ \\
\hline Control Group & $\mathrm{O} 3$ & $\mathrm{X} 2$ & $\mathrm{O} 4$ \\
\hline $\begin{array}{l}\text { O1, O3: indicates pre-test } \\
\text { O2, O4: indicates post-test }\end{array}$ & & \\
X1: indicates Integration of LEGO robots into instruction X2: indicates \\
raditional teaching method
\end{tabular}

\section{B. Limitation}

1) This study is not able to expand its research objects to the automobile departments in vocational schools nationwide, thus the results of this study are only expressed whether the integration of LEGO robots into instruction of the engine principles and practice curriculum can improve students' learning effectiveness .

2) While these students (research sample) enrolling this school research sample, they have been grouped according to individual interest, however it still has possibility of occurring Hawthorne and John Henry effect in the process of experiment.

\section{DATA ANALYSIS AND DISCUSSION}

This study intends to understand the teaching experimental results of the integration of LEGO robots into instruction, and analyze and discussion, which is divided into four sections as follows.

\section{A. Analysis of Sample Data}

It adopted students of two 1st-year classes from the 
automobile department of a private senior high school in Changhua County as the research object, due to these students had been given the aptitude grouping when they were enrolled, thus it applied the purposive sampling to assign one class as the control group (Automobile 1st Year Class 1) with total 48 students, and the other class as the experiment group (Automobile 1st Year 2) with total 48 students, which the effective sample size is 96 students, as shown in Table II:

TABLE II: RESEARCH SAMPLE SIZE STATISTICS TABLE

\begin{tabular}{lcl}
\hline Group & Size & Percentage (\%) \\
\hline Experiment Group & 48 & 50 \\
\hline Control Group & 48 & 50 \\
\hline Total & 96 & 100 \\
Size: sample number of the group
\end{tabular}

\section{B. Analysis of Subject's Learning Effectiveness}

The pre-test result of the learning effectiveness for the engine principles and practice subject in the experiment group (35. 28 points) is lower than the one in the control group (38. 54 points); in terms of post-test results, the experiment group (83. 17 points) is higher than the control group (72. 71 points).

After carried out the independent-sample $t$-test on the scores of learning effectiveness (pre-test) for the engine principles and practice subject, $t=1.811, p=.073>.05$, the result has not yet reached the of significance, which indicated that before carrying out the experimental teaching for both the control group and experiment group, these two groups' students didn't have significant difference in their basic background for the engine principles and practice.

After eliminated the influence on the pre-test scores, it is herein investigated whether or not it achieved a significant effectiveness within these two aforesaid teaching methods; in addition, tool the different teaching method as the independent variable (A), the pre-test of learning effectiveness on engine principles and practice as the covariable (Y), and the post-test result as the dependent variable $(\mathrm{X})$.

TABLE III: LEVEL OF LEARNING EFFECTIVENESS

\begin{tabular}{lllll}
\hline \multirow{4}{*}{ Group } & $\begin{array}{l}\text { Learning } \\
\text { Effectiveness } \\
\text { ability grouping }\end{array}$ & $\begin{array}{l}\text { Pre-test } \\
\text { Average } \\
\text { Points }\end{array}$ & $\begin{array}{l}\text { Post-test } \\
\text { Average } \\
\text { Points }\end{array}$ & $\begin{array}{l}\text { Improved / } \\
\text { Retrograde }\end{array}$ \\
\hline \multirow{3}{*}{ Control Group } & High & 49.23 & 74.62 & 25.39 \\
\cline { 2 - 5 } & Middle & 38.75 & 74.27 & 35.52 \\
\cline { 2 - 5 } & Low & 27.50 & 68.15 & 40.65 \\
Experiment & High & 45.00 & 82.15 & 37.15 \\
\cline { 2 - 5 } Group & Middle & 35.80 & 84.09 & 48.29 \\
\cline { 2 - 5 } & Low & 24.69 & 82.62 & 57.93 \\
\hline
\end{tabular}

Regardless of the control group or experiment group, in these 3 levels (high, middle and low) of learning effectiveness, all of them are improved significantly; especially in the experiment group (as in Table III), which indicates that after implemented the integration of LEGO robots into instruction, the average scores of experiment group are significantly higher than students of the control group. Students with lower learning effectiveness, their scores are improved the most with 57.93 points, and students with middle and low learning effectiveness, their average scores are also improved 48. 29 points and 37.15 points, respectively. In terms of the control group, students with higher learning effectiveness, their average scores are improved 25.39 points, and students with middle and lower learning effectiveness, their average scores are improved 35.52 points and 40.65 points respectively, but they are not as good as the improved scores for students of the experiment group. Therefore, after implemented the integration of LEGO robots into instruction, students' learning effectiveness in the experiment group is higher than the ones of the control group, and they have significantly improved in different levels, especially it significantly affected students with lower learning effectiveness.

\section{Practical Subjects Learning Effectiveness Analysis}

For these two abilities of practical subjects: "disassembly, assembly and measurement of four-stroke single cylinder piston" and "investigation of fuel injection engine components and use of diagnostic apparatus", the percentage of pass is $52.1 \%$ for the control group, and $83.3 \%$ for the experiment group, which indicates that after integrating LEGO robots into teaching, students of the experiment group have better concept of automatic control than ones of the control group. From Table IV, it showed that 19 students of the control group passed both subjects and occupied a percentage of 39. 6\%; however, 40 students of the experiment group passed both subjects and occupied $83.3 \%$ of the total population, which indicates that after integrating LEGO robots into teaching, students of the experiment group have been improved their abilities of mechanical structure and automatic control, as well as better than ones of the control group. That is, after implementing different teaching methods to the control group and experiment group, it showed a significant difference between their learning effectiveness of practical subjects.

TABLE IV: TECHNICAL COURSE LEARNING OUTCOMES

\begin{tabular}{llllll}
\hline Group & $\begin{array}{l}\text { Total } \\
\text { Population }\end{array}$ & $\begin{array}{l}\text { Test } \\
\text { Question 1 }\end{array}$ & $\begin{array}{l}\text { Test } \\
\text { Question 2 }\end{array}$ & $\begin{array}{l}\text { Population } \\
\text { passed both } \\
\text { Tests }\end{array}$ & $\begin{array}{l}\text { Percentage } \\
\text { passed both } \\
\text { Tests }\end{array}$ \\
\hline $\begin{array}{l}\text { Control Group } \\
48\end{array}$ & 34 & 25 & 19 & 39.6 \\
\hline $\begin{array}{l}\text { Experiment } \\
\text { Group }\end{array}$ & 48 & 48 & 40 & 40 & 83.3 \\
\hline
\end{tabular}

\section{Analysis of Learning Attitude}

\section{1) Analysis of learning attitude}

Respectively implemented the independent-sample $t$-test on each aspect of learning attitude for the control group and experiment group, as showed in Table $\mathrm{V}$, in the learning attitude questionnaire of "experiment of integrating LEGO robots into the automobile department in vocational school engine principles and practice curriculum", the average scores of each aspect of the experiment group are higher than the control group, which indicates that students' learning attitude of the experiment group is higher than the ones of the 
control group.

\section{2) Analysis of variance (ANOVA) for learning attitude}

Students with higher scores for these 5 aspects achieved the significant difference, which indicates that students of the experiment group with high performance whose learning attitude of each aspect is higher than those students of the control group with higher scores. However, there's no significant difference for students with low performance of both groups, which indicates that among students with low performance, regardless of the control group or the experiment group, after implemented different teaching methods, there won't be any difference in their learning attitude.

TABLE V: ANALYSIS OF LEARNING ATTITUDE

\begin{tabular}{|c|c|c|c|c|c|c|}
\hline (A) & (B) & (C) & (D) & (E) & $(F)$ & Sig. of F \\
\hline \multirow{3}{*}{1} & $\mathrm{a}$ & 48 & 3.83 & .593 & \multirow{3}{*}{8} & \multirow{3}{*}{$-2.850^{* *}$} \\
\hline & & & & & & \\
\hline & $\mathrm{b}$ & 48 & 4. 17 & .580 & & \\
\hline \multirow{3}{*}{2} & $\mathrm{a}$ & 48 & 3.90 & .497 & \multirow{3}{*}{6} & \multirow{3}{*}{$-2.470^{*}$} \\
\hline & & & & & & \\
\hline & $\mathrm{b}$ & 48 & 4. 19 & .625 & & \\
\hline \multirow{3}{*}{3} & $\mathrm{a}$ & 48 & 3.78 & .529 & \multirow{3}{*}{8} & \multirow{3}{*}{$-2.322^{*}$} \\
\hline & & & & & & \\
\hline & $\mathrm{b}$ & 48 & 4. 06 & .651 & & \\
\hline \multirow{3}{*}{4} & $\mathrm{a}$ & 48 & 3.41 & .599 & \multirow{3}{*}{-7} & \multirow{3}{*}{$-3.606 * *$} \\
\hline & & & & & & \\
\hline & $\mathrm{b}$ & 48 & 3.88 & .692 & & \\
\hline \multirow{3}{*}{5} & $\mathrm{a}$ & 48 & 3.47 & .567 & \multirow{3}{*}{$\_8$} & \multirow{3}{*}{$-5.014 * * *$} \\
\hline & & & & & & \\
\hline & b & 48 & 4. 07 & .593 & & \\
\hline
\end{tabular}

$* p<.05, * * p<.01, * * * p<.001$
(A) : Aspect
(B) : Group
C) : Population
(D) : Average
(E) : SD
(F) : No. of Questions

After implemented different teaching methods to students with high performance, their learning attitude toward the learning effectiveness of practical subjects would achieve significant difference in 3 aspects, such as "learning environment", "teaching curriculum" and "peer friends", and students of the experiment group have higher scores than the ones of the control group.

\section{CONCLUSIONS AND SUGGESTIONS}

\section{A. Conclusions}

As the results of this study showed, after implemented the integration of LEGO robots into instruction, students of the experiment group had better learning effectiveness of practical subjects than the control group, therefore the integration of LEGO robots into instruction will cause a better learning effectiveness of engine principles and practice subjects and curriculum than traditional teaching.

In addition, after applied the integration of LEGO robots into instruction, students of the experiment group had higher scores of learning attitude toward engine principles and practice curriculum than the control group.

Thus, as the aforesaid research results showed, students of the experiment group will have higher scores than the control group for the learning effectiveness either on regular subjects or practical subjects. In addition, with matching others' or one's own anticipation, so that yielded higher learning motivation and learning attitude, which is conformed to the research outcome that made by Yi-Chern Hsieh, Jian-sheng Huang and Jian-hong $\mathrm{Lu}$ [7]; that is, the learning effectiveness and learning attitude are affected mutually, higher learning effectiveness will have higher learning attitude, otherwise lower.

\section{B. Suggestions}

According to the research results, this study proposed several suggestions for the integration of LEGO robots into the teaching of engine principles and practice and future researches as the reference to follow-up studies.

\section{1) Suggestions to teachers who applied LEGO robots to implement the integration into instruction}

In order to increase students' learning willingness, they can set the definite reward method for classes of integrating LEGO robots into instruction before implementing the experimental teaching, and then based on the teaching contents by units or topics, so as to improve students' learning effectiveness of implementing the experimental instruction of LEGO robots.

\section{2) Suggestions to schools}

This research result showed that LEGO robots can be a official auxiliary teaching material for regular curriculum; however, as being a teaching material, LEGO robots won't be always the same and will be varied constantly, the developing company of LEGO products will depend on the soft/hardware equipment and device in the current market to constantly develop more advanced LEGO robots; as a result, schools can purchase related LEGO robots and soft/hardware equipment as required, so as to improve their students' learning effectiveness.

\section{3) Suggestions to follow-up researches}

For follow-up researches, they may explore by focusing on students' background conditions, such as students of public vocational high schools, and the implementation of 12-year compulsory education project, then set the teaching design with various levels to investigate students' learning effectiveness of integrating of LEGO robots into instruction learning effectiveness .

\section{REFERENCES}

[1] T.-C. Lin and Y.-Y. Lee, "Policy and development in technical and vocational education," Quarterly Journal of Technological and Vocational Education, vol. 1, no. 1, pp. 6-16, 2011.

[2] T.-M. Lin, "Incubation policy of technical and vocational education talents," Quarterly Journal of Technological and Vocational Education, vol. 2, no. 1, pp. 2-6, 2011.

[3] C.-H. Lee, "The study of learning effectiveness difference between new and old curriculums for students at automobile departments in vocational schools," M.S. thesis, Dept. of Education, National Dong Hwa University, Hualien, Taiwan, 2009.

[4] J.-C. Cheng, Minutes of 2008 MOE Vocational Schools Course Groups, South Region Counselling and Advisory Session, 2008.

[5] Exam subject chart of single course group (classification) for academic year 2013 four/two-year college program entrance exam quoted. Testing Center for Technological and Vocational Education. [Online]. Available: http://www. tcte. edu. tw/four/page102_maj4. htm 
[6] J.-J. Chen, "A study of reflection and improvement in new curriculum at vocational high schools," Journal of Education Research, vol. 149, pp. 33-37, 2006.

[7] Y.-C. Hsieh, J.-S. Huang, and J.-H. Lu, "A case study of investigating the influence of relationship on learning attitude of technical and vocational education students," Journal of National Huwei University of Science \& Technology, vol. 6, pp. 99-110, 2003.

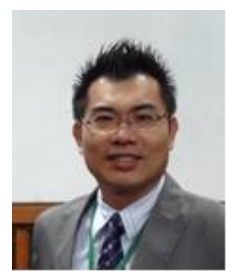

Tsai-Ku Liao received the M.S. degree at the Department of Geography from National Taiwan Normal University in 2006, and currently he is a Ph.D candidate at the Department of Industrial Education from National Changhua University, Taiwan, R.O.C. Since August 2008, he has been a director of Student Affairs and Library in National Taichung First Senior High School (TCFSH) in Taiwan, R.O.C. Since August 1998, he has taught courses in geography, GIS, monographic study in the same school.

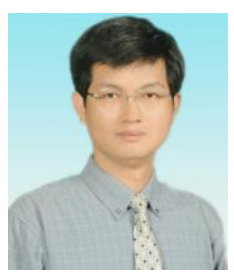

Chin-Wen Liao received both the M.S. and Ph.D degrees in industrial education from National Taiwan Normal University, Taiwan, R.O.C. in 1994 and 2002, respectively. Since August 2011, he has been a professor in the Department of Industrial Education and Technology at National Changhua University of Education (NCUE) in Taiwan, R.O.C. At the same time. He teaches courses in technology and vocational education, energy education, teacher education, course and teaching, organization learning. His research interests include technology and vocational education, energy education of technology, automatic control, and knowledge management.

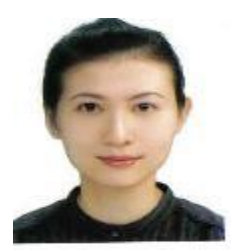

Chia-Ling Shih is a doctoral student of the Department of Industrial Education and Technology, National Changhua University of Education (NCUE), Taiwan and now a high school teacher in Taiwan, Taichung.

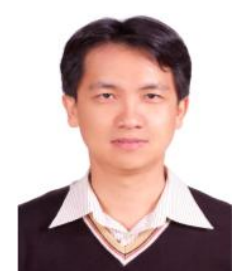

Chang-Fu Lin received the M.S. degree at the Department of Graduate Institute of Primary and Secondary Education from National Chiayi University University in 2003, and currently he is a doctora student at the Department of Industrial Education from National Changhua University, Taiwan, R.O.C. Since August 2012, he has been a director of General Affairs Office in Tonan Senior High School in Taiwan, R.O.C Since August 2000, he has taught courses in everyday science technology in the same school. 